\title{
EXAMINING THE POTENTIAL VALUES OF VERNACULAR HOUSES IN THE ASIR REGION OF SAUDI ARABIA
}

\author{
HAITHAM SAMIR ${ }^{1}$, ANNA KLINGMANN ${ }^{1} \&$ MADY MOHAMED ${ }^{1,2}$ \\ ${ }^{1}$ College of Architecture and Design, Effat University, Saudi Arabia \\ ${ }^{2}$ Zagazig University, Egypt
}

\begin{abstract}
Most of the Saudi Arabian regions, in general and Asir in particular, are characterized by traditional settlements, which reflect the social and cultural values of vernacular communities. These communities and their traditional architecture defined, until recently, the nuclei of many cities and towns. The accelerating urban growth and lack of interest of the local population in their vernacular heritage have led to negligence and subsequently to the demolition and removal of many buildings of significant cultural value. As long as such practices persist, cities and towns risk the loss of their identity and cultural diversity. The purpose of this paper is to investigate potential values inherent in the vernacular housing stock of Asiri villages and to allow these structures to become an active part of the contemporary life of cities as well as a valuable heritage resource for future generations. Before deciding on the significance of preserving and safeguarding the vernacular housing stock of the Asiri highlands and the role it may play for present and future generations, it is necessary to have a thorough understanding and acknowledgement of the values emerging from it. Thus, the paper employs an expert appraisal approach through the utilization of a detailed architectural survey, analysis and subjective assessment of two traditional mud houses. The two houses typify the characteristics of Asiri mud architecture. A self-directed questionnaire with a group of local owners of such houses was conducted to investigate whether they see value in their vernacular heritage and whether or not they might be interested in reutilizing their traditional mud houses, which currently sit empty, for contemporary and future applications. This paper points to the significant potential of applying a value assessment as a tool to inform a sustainable conservation practice dependent upon the interplay of social, cultural and environmental values associated with the housing stock of Asir.
\end{abstract}

Keywords: vernacular architecture, heritage values, Asir region, mud houses.

\section{INTRODUCTION}

Asir has approximately 400 traditional settlements of stone and mud architecture, which currently lie in a state of abandonment and decay. The objective of this paper is therefore to foster an awareness of the benefits of vernacular settlements in the southwest, which are rapidly disintegrating. This necessitates an exploration of the potential value of these settlements - in terms of their cultural considerations, their sustainable performance and economic value. The latter seems of special importance, as most of the houses in the settlements are still privately owned. While the owners of vernacular properties seem to appreciate their houses on a sentimental level, largely as a tribute to their ancestry, they do not see a prospective monetary return and thus, most leave their vernacular properties to decay. According to a study conducted by Mohammed Bagader, the majority of Saudis appreciate their heritage, but at the same time, they prefer to live in large western-style villas of concrete-block construction [1]. Many of the respondents argue that it is the government's responsibility to preserve and rehabilitate historic heritage sites even if they are privately owned and the respondents happen to be the owners of these properties. Only a very small minority of proprietors attempted to restore and upgrade their properties without the financial support from the government. Most of them faced an assortment of variegated obstacles that 
typify the situation of implementing a restoration project, and which they summarized as follows: lack of restoration techniques, shortage of traditional materials, lack of monetary support, legal issues due to the big number of heirs, strict building regulations. In addition, the government is not involving them in any of the larger decision-making processes of conservation efforts.

Many experts believe that the lack of awareness of the importance of conserving the builtheritage sites, along with the dependence on government initiatives, has contributed to the progressive decay and destruction of traditional settlements in the southwest. The second issue is that not only the physical structures but also the builders' knowledge is quickly disappearing if indeed it is not being promoted and shared among generations and academic institutions. The Asir region has a disproportionally high number of people over sixty years old since the younger generation progressively left this very rural region over the past thirty years for fulltime employment in the major metropolitan areas. Some of the older people still retain valuable builders' knowledge but since the onset of standardized concrete construction, most have no longer practiced their traditional skills and are currently living off pension funds. The question is how one might re-engage some of these artisans and have them actively participate in preserving Saudi Arabia's heritage by encouraging them to pass on their vernacular building practices to younger generations, to bring these skills into the $21 \mathrm{st}$ century. This is even more important since Saudi Arabia as a nation is striving to conserve their cultural heritage, engage people from rural regions in meaningful work and activities, while simultaneously seeking to conserve energy by implementing sustainable practices.

\section{LITERATURE REVIEW}

Vernacular cultures, globally, are in a time of transition. Historic mountain villages in Arabia and elsewhere that may warrant protection from a cultural point of view rapidly disappear due to migration, neglect, and abandonment. Yet, as argued by many researchers, vernacular settlements signify important tangible cultural capital. As such, built vernacular heritage constitutes the physical expression of the specific culture of a regional community and of its relationship with its respective territory. In addition, vernacular heritage, when seen on a global scale, is also an important document of the world's diverse cultures [2]. Intangible cultural capital, as opposed to physical heritage, exists in certain traditions, belief systems, the combination of human skills, building techniques and social structures [3]. Both together tangible and intangible cultural capital - define the cultural heritage of a region and hold a priceless source of scientific and cultural knowledge for which it should be preserved [4], [5]. Cultural heritage also provides a variety of socio-economic functions, which includes aesthetic and emotional pleasure, a sense of place and identity, opportunities for education and training, economic benefits through tourism development, and inspiration for scientific research and learning [6]. In addition, many vernacular habitats are unique and, thus, not substitutable. Once demolished, no man-made capital can recreate them. For these reasons and many others, cultural heritage is valuable to different societies. While social value cannot necessarily be quantified in economic terms only, through traditional market transactions, there is undoubtedly a relationship, as Klamer demonstrates in the need to assess the contribution of cultural assets to economic profit. But he also points out that, unlike economic capital, most of the cultural assets should not be assessed in purely economic terms, which generally points to the utilitarian value of good; but that cultural capital can have a value in its own right with its capacity "to inspire and be inspired". Cultural capital is able to give meaning to objects and, ultimately, to human life [7]. Furthermore, Klamer argues that cultural assets are collective possessions and they need to be shared in order to be meaningful. Therefore, cultural resources, quite like environmental goods, are generally considered as 
public goods [4]. Ruijgrok describes the necessity to valuate cultural heritage even though its real value cannot be expressed in financial terms [8]. From this perspective, he argues that the economic valuation of cultural heritage makes it possible to evaluate investments in this sector through cost-benefit analysis and to estimate the losses incurred by society through the destruction of cultural heritage.

Lastly, cultural heritage is also the physical representation of a community identity that demands to be passed on to others. Preserving the environment for future generations is one of the key concepts of sustainability, which refers to the need for intergenerational equity [8]. Applying the theory of sustainable development to cultural capital, Throsby refers to the fact that if the stock of cultural capital is diminished, or even consumed, future generations will not be able to benefit from its knowledge and resources [3]. In conclusion, many researchers in the field of cultural economics certify the importance of vernacular settlements as valuable cultural capital with its impact reaching far beyond the economic sphere into the realms of sustainability, education and social well-being.

\section{DETERMINATION OF FRAMEWORK FOR VALUE ANALYSIS}

The specific vernacular and cultural heritage of the Asiri highlands is presently not regarded as a local or national concern. Therefore, its relationship with social values, economic activities, and local development has to be closely examined and evaluated. The evaluation should primarily be based on the physical analysis of the vernacular stock in question as a part of Asir's architectural heritage and cultural landscape. Together with the architectural characteristics, the values that make the vernacular settlements eligible for conservation and safeguarding should be clearly defined through the stated opinion of the local residents. Since the starting point of conservation studies is based on the definition of the significance of heritage buildings [10], the evaluation must establish certain criteria to be adopted in recognizing the potential values associated with traditional mud architecture. The identification of this significance has considerable value for the justification of any conservation initiative. The mutual relation between conservation and value is interlinked as conservation process begins with understanding cultural value of the element being conserved. At the same time, conservation should not detract from the value itself. Rather, it should assert its continuity. Identifying the features that give a building its heritage significance refers to all its tangible and intangible aspects [2]. The following criteria have been developed in respect of the value and worth of the buildings attributed to it according to the degree of its architectural and contextual features, cultural importance, and contemporary utilitarian potentialities. The use of these sources permits elaboration of the specific artistic, historic, social and scientific dimensions of the cultural heritage to be examined.

\subsection{Architectural and contextual features}

With regard to the conceptual framework of this study, the tangible aspects of the architectural characteristics are identified by their external and internal spatial organization, aesthetic appearance, construction materials and façade order.

\subsection{Cultural value}

This intangible cultural heritage, transmitted from generation to generation, is constantly recreated by the local communities and groups in response to their environment, their interaction with nature and their history, and provides them with a sense of identity and 
continuity, thus promoting respect for cultural diversity and human creativity [11]. The research, through its applied methodology, tries to explore and document these traditional practices, which shaped the vernacular housing stock of Asir over several centuries and points at the importance of the transmission of such old techniques and practices to the coming generations.

\subsection{Contemporary utilitarian economic potentialities}

The valorization of vernacular mud architecture constitutes a factor of attraction, not only for tourists but also for the local residents who see it as a valuable asset, which could contribute to the whole community through the implementation of new activities and for utilizing it as a place for their gatherings. In conservation practice, sustainability is the continuous utilization of the built heritage, adapting present needs and lengthening the life of the heritage recourse [12]. Sustainable reuse proposals pass the value of vernacular buildings to subsequent generations and enrich the local cultural and economic statues [13].

\section{METHODOLOGY}

Based on the previous literature review and the proposed framework for value analysis, it is necessary to have a thorough understanding and acknowledgement of the values emerging from traditional Asiri architecture. Thus, the paper employs two approaches for value assessment that are widely applied in this field: the expert appraisal and social anthropology.

\subsection{Expert appraisal approach}

Mason argues that the conservation field has traditionally relied on expert appraisals (by art historians, architects, and archaeologists) for guidance on the merit to conserve [14]. It is important for this research to rely on documentary methods to analyze the physical conditions of the vernacular housing stock in question. The values themselves and conservation decisions typically stem from judgments that are made by a scholarly expert trained in the canons of taste, authenticity and historical significance. Thus, the first tool applied in this research is a detailed architectural survey and a spatial analysis of two traditional mud houses, which are located in two small towns, Al-wadeen and Al-Osran, in the highlands of Asir. The two houses are representing, largely, the typical characteristics of Asiri mud architecture.

With regard to understanding the architectural and contextual features, both buildings were recorded graphically and by photographic capturing, describing their respective physical configurations and conditions. The buildings were measured manually by using a 20 -meter steel measuring tape, a laser distance meter, pencils and graph paper. The measurements were transcribed directly to an AutoCAD file, which provided a final check on the measurements. Where discrepancies existed, the measurements were re-checked the following day. The process of recording the buildings allowed the research team to become familiar with the spatial organization of the building spaces, materials and common architectural features. Following this process, plans, sections and elevations were created.

\subsection{Social anthropological approach}

Expert appraisals constitute an important input to value assessment, although, more recently, they tend to be combined and integrated with other kinds of assessments, which are more closely attuned to capturing the values of other stakeholders such as the local people [14]. Ethnographic approaches seem most appropriate to the heritage conservation task because of 
Table 1: Products and outcomes of the research methods used.

\begin{tabular}{|c|c|c|c|}
\hline $\begin{array}{c}\text { Approach/ } \\
\text { method }\end{array}$ & Data & Product & $\begin{array}{c}\text { What can be } \\
\text { learned }\end{array}$ \\
\hline $\begin{array}{c}\text { Expert } \\
\text { appraisals }\end{array}$ & $\begin{array}{c}\text { Architectural } \\
\text { survey and } \\
\text { documentation }\end{array}$ & $\begin{array}{c}\text { Description of the vernacular } \\
\text { houses forms the experts' } \\
\text { points of view }\end{array}$ & Expert judgments \\
\hline $\begin{array}{c}\text { Social } \\
\text { anthropology }\end{array}$ & $\begin{array}{c}\text { Questionnaire } \\
\text { survey data } \\
\text { sheets }\end{array}$ & $\begin{array}{c}\text { Description of the vernacular } \\
\text { houses form community } \\
\text { members' points of view }\end{array}$ & $\begin{array}{c}\text { Community } \\
\text { response and } \\
\text { interest }\end{array}$ \\
\hline
\end{tabular}

their group level of analysis [15]. Stemming from this concept, the research has jointly employed an ethnographic method using a qualitative data collection process for uncovering local community knowledge. This helped in synthesizing information about the social and physical context and using this information to elicit specific cultural values of the local community, understanding the meanings that vernacular houses hold for them and giving voice to their concerns and perspectives. Thus, the research employed a self-directed questionnaire, which was handed to a demographically diverse group of local people with the objective to investigate how they value their traditional houses and how they view the prospects of reusing them for contemporary and future needs. During this process, the researchers took notes and recorded the vital points. Later, the responses were analyzed to assess the value stated by the responders, especially those related to cultural importance and contemporary utilitarian potentialities.

\section{ANALYSIS OF THE ARCHITECTURAL AND CONTEXTUAL FEATURES}

The architectural survey and documentation revealed several interesting features that shape the vernacular mud houses including the buildings' interrelation with their environment, their spatial organization, construction materials and façades.

\subsection{Analysis of a building in relation to its environment and setting}

The vernacular architecture of Asir is to a great extent dependant on the geography and the climate of the area and of the local materials such as mud and stone [16]. The Asiri house, in particular, is representing a characteristic type of vernacular architecture in Saudi Arabia. Its use, construction and physical layout reflect endemic traditions and values in which the expression of cultural values, social practices, and environmental conditions over time is manifested in physical features and materials and their interrelationships. Local materials proved to balance the fluctuation between summer heat and winter cold. This traditional house-form is an architecture without architects and generations of villagers have practiced the same pattern of construction over centuries. The building delivery process was pursued through a celebratory community collaboration where each individual in the community could share in the whole process.

\subsection{Analysis of spatial organization}

The Asiri house was designed to provide shelter for man and tamed animals such as sheep and goats. The building consists of one ground and two upper floors. Spaces of the ground floor were dedicated to animals, poultry and stores for grains and seasonal crops. The main 
sitting room occupied a considerable part of the first floor, while the top floor typically accommodated sleeping rooms for the family and a kitchen. An open terrace was typically added to the upper floor for washing purposes. A staircase, built of mud and supported by wooden beams, vertically connects the floors. It occupies a large space with a thick wall in the center between the flights to support the entire staircase (Figs 1,2).

\subsection{Analysis of construction materials}

The prevalent construction material of the Asiri houses is mud, extracted from the local soil, added to the local stone which is essential to support the mud consistency. A frequent use of local timber is used as roofing material. The houses are often built on stone strip footings or natural rock followed by subsequent courses of mud. The prevalent thickness of the walls is about 50-90 centimeters, which is sufficient to support the three floors of a mud building. Mud layers are applied one on top of the other so that the previous layers can dry before the next one is added. The exterior walls lean inwards allowing for less thickness in the upper floors. It worth mentioning here that the mud as a traditional construction material contributes to the thermal performance of the building, but it is important to use it in combination with other appropriate passive design strategies and measures [17].

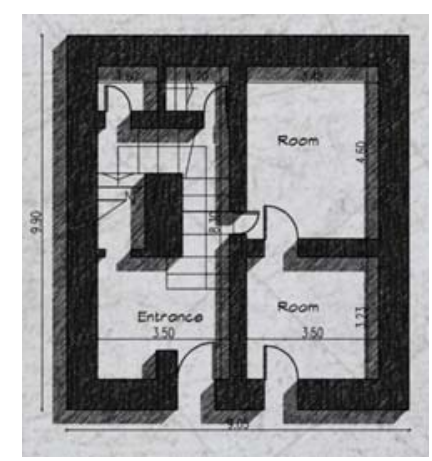

(a)

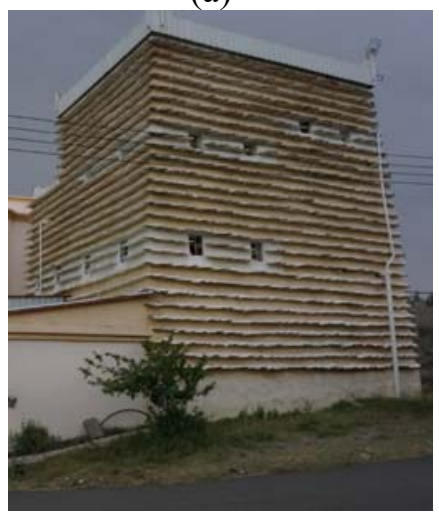

(d)

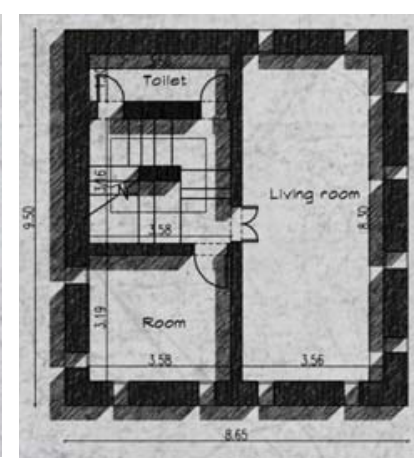

(b)

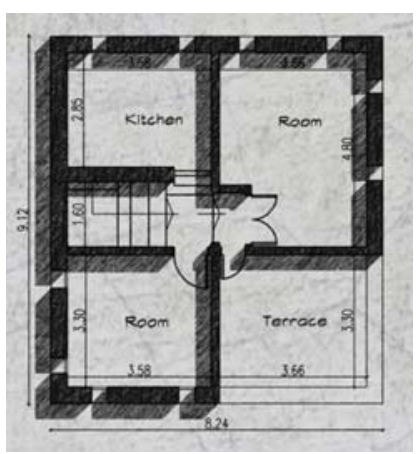

(c)

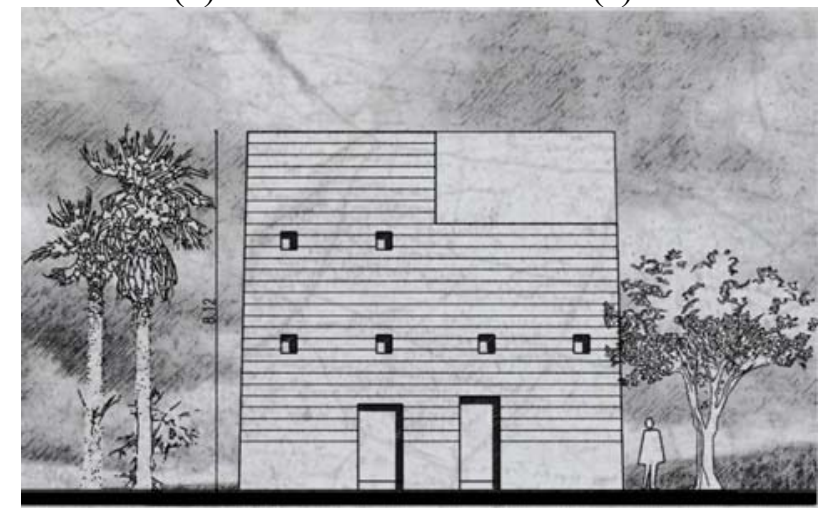

(e)

Figure 1: House at Al-Osran. (a) Ground floor plan; (b) Second-floor plan; (c) Roof plan; (d) Street elevation; (e) Main entrance elevation. 


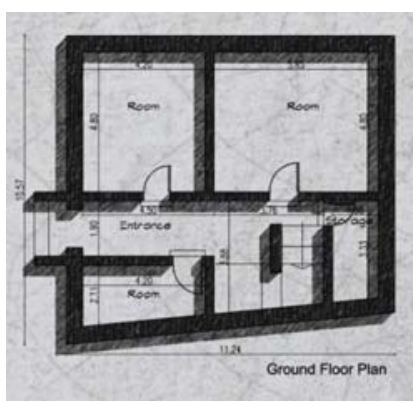

(a)

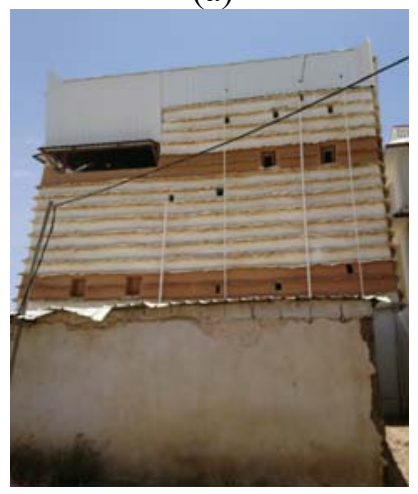

(d)

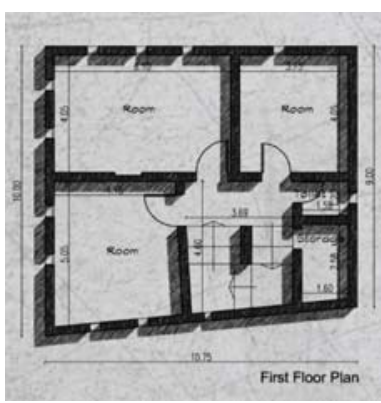

(b)

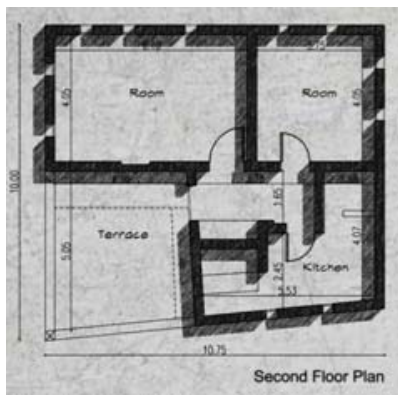

(c)

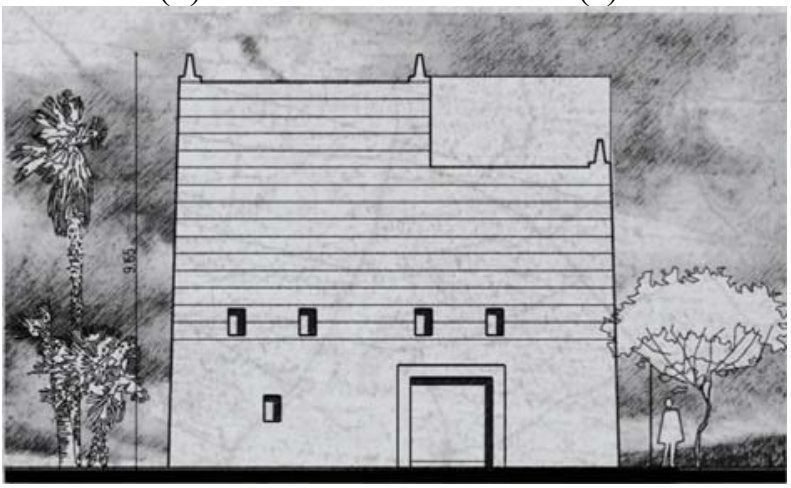

(e)

Figure 2: House at Al-Wadeen. (a) Ground floor plan; (b) Second-floor plan; (c) Roof plan; (d) Street elevation; (e) Main entrance elevation.

\subsection{Analysis of façades}

The exterior walls feature small openings. Walls continue above the roof parapet as pointed decorative elements. Applying repetitive rows of slates that have been inserted into the walls played a significant role in protecting the exterior walls from the rainwater and added a special character to the traditional house in Asir. The slates give a striated effect to the elevations, which is often accentuated by horizontal bands that were painted in a variety of colors. Since the mud house needs continuous maintenance to protect it from the adverse effects of weathering, many of the residents have decided to cover their mud houses with corrugated steel sheets. This prevailing treatment has negatively affected the aesthetic character of the vernacular housing stock (Figs 1,2).

\section{ANALYSIS OF THE CULTURAL VALUE AND UTILITARIAN ECONOMIC POTENTIALITIES}

The questionnaire targeted a sample of 18 participants from two villages of the Asiri highlands: Al-Osran and Al-Wadeen. All the participants who were involved in the questionnaires have lived in Asir for more than 10 years. Only two participants have moved out to the major metropolitan cities of Riyadh and Dammam. Respondents were selected randomly from households. The survey was administrated by two groups of students on a face-to-face basis over a course of three days. Each group contained three students supervized by an instructor. 


\subsection{The social profile of the participants}

The questionnaire focused on people with different professions and generations, in order to develop an overall understanding of how people with different backgrounds and ages view their vernacular heritage. The majority of the respondents' own mud houses, which were built by them and their family members or inherited from their fathers or grandfathers. Growing up in Asir seemed to be a privilege to all the participants that were interviewed. Most Asiris feel a great attachment and belonging to their land, strengthened by a strong commitment to their respective community. They appreciate the ways they relied on local resources to meet their needs for food as well as for shelter, however, this has changed nowadays by shifting to modern technology and newly manufactured materials that are characterizing this era. An example of this is the new varieties of building materials have been introduced, most of which are not indigenous represented by reinforced concrete, concrete blocks and even prefabricated metal and glass buildings.

\subsection{Participants' perception of their mud houses}

Participants mentioned that the construction of mud houses stopped in the 1980s when the concrete house became the prevailing mode of construction within the region. The majority of the respondents stated that it took them approximately between 6-12 months to build a mud house. Over time, the traditional appearance of the mud house was modified by adding asphalt or cement to the house to maintain its ground floor stability. The interior was changed either by repainting, adding rooms, upgrading facilities with plumbing fixtures, or changing the functions of rooms from animal storerooms to family rooms. Although most mud houses in this area have only three floors, there are also houses with four and five floors. The number of rooms inside the houses ranges from four to eight rooms depending on the size and the number of levels. Toilets were traditionally placed outside the house to keep the sewage away from the buildings, but many mud houses have been retrofitted with an in-house toilet in the late twentieth century. Mud houses were built this way because they followed the traditional method of construction within the area. The materials used for the construction were brought from the local region and typically comprise mud, slats, and timber. Women painted the walls of interior spaces and elements with either decorative traditional patterns or plain colors especially prior to major family ceremonies and celebrations. The most elaborately decorated space of the house was the majilis as it would serve as the center of the house where all family members and friends used to gather.

\subsection{The stated cultural values of the mud houses}

The majority of the respondents expressed a desire to safeguard the traditional mud houses because they feel that these structures are a part of their cultural identity, which ought to be passed to future generations as a source of attaching people to their roots. However, a few respondents linked their desire to safeguard their houses in favour of assuring their right to the entire property in which the house is located. They appreciate the mud house for its passive means for ventilation since the mud as a construction material helped to maintain a thermal comfort for the occupants during the summer and the winter months. Without the need for modern air conditioners, people lived a more active life and felt comfortable in their houses. Finally, most of the respondents expressed a consensus about the cultural significance of traditional houses of Asir as physical evidence for the interaction between people and their respective environments. 


\subsection{The preferences towards the re-utilization of the mud houses}

However, many owners stopped maintaining their mud houses since they moved to modern concrete villas, however, the survey reported that $40 \%$ of the sample did not stop the regular maintenance necessary to maintain their mud house as gathering places for their families or to safeguard the house as a tribute to their ancestors. The rain was considered to be a most hazardous factor affecting the house as it results in the degradation of the mud. $60 \%$ of the respondents are lacking information or ideas about how they might creatively reuse and make a profit of their houses. $27 \%$ showed their commitment to renovate their houses for personal use, and only $13 \%$ favor the concept of transforming it for a touristic purpose. When new uses were proposed to them, the majority preferred to reuse their houses for private purposes such as a place for congregation for family and friends. Only $25 \%$ showed a willingness to adapt them for a public or touristic use. All respondents, however, expressed interest to preserve their mud house as a document of their culture that should be handed to the future generations along with traditional mud construction techniques.

\section{EVALUATION}

Without doubt, the vernacular housing stock of Asir, although suffering from various degrees of obsolescence and degradation, offers potential as a cultural capital. Throsby argues that cultural capital like any capital item exists both as a stock of assets and as a flow of capital services over time [18]. Either way, the particular characteristic of cultural capital is that it embodies two types of value: economic and cultural.

In regard to the economic value, a distinction is usually made between use and non-use value. In the case of the Asiri mud houses, use value may refer to the direct utilization of the asset by those who consume it - the revenue brought by the house in case of its reuse, for example. Non-use value refers to the asset's existence value (respondents valued the existence of their vernacular houses even though they may not consume its services directly themselves); its option value (respondents wished to maintain the option that they or their sons might consume the asset's services at some future time); and its bequest value (respondents wished to bequeath their vernacular assets to the future generations).

In regard to cultural values, Drury and MacPherson argue that some values can be appreciated as culturally conditioned responses [19] (for example, an aesthetic response to a building), but the experience of all heritage values tends to be deepened through specific knowledge about the place. Throsby, moreover, identified elements, which are contributing to the aggregate cultural value, including aesthetic value, spiritual value, social value, historical value, symbolic value and authenticity value [18].

The traditional mud houses, which are indigenous to the Asir region, have several qualities with respect to cultural values. They form a regional identity, which stems from their specific form, size, materials and architectural elements. One of the most striking and well recognizable relationships between society and environment is the symbolic role of architecture as a symbol to establish and affirm the physical identity of place [20]. A place possesses a sense of identity when fostered by distinctive artifacts and objects that are important to its definition [21]. It worth mentioning that the traditional mud houses of Asir depict the place's uniqueness and individuality and they contribute to its physical identity along with other spatial components. Their ties, bonds and affiliations with the place and the larger culture are aspects of space identity. Although the indigenous master builders had attempted to develop their distinctive character, major changes have taken place in new buildings. The vernacular house was discarded in favor of the modern concrete villa, which 
Table 2: Assessing the values of traditional Asir houses based on the research outcomes.

\begin{tabular}{|c|c|l|}
\hline Values & Sub-type & \multicolumn{1}{c|}{ Description } \\
\hline Economic & Use value & $\begin{array}{l}\text { Respondents value their mud structures for the reason of their } \\
\text { possible (direct) re-utilization. The case of Al-Osran house } \\
\text { represented this idea, where the owner was able to bring a new } \\
\text { life to his old structure and decided to renovate his mud house } \\
\text { and uses it as a family retreat and for guests. The house is open } \\
\text { for visitors, and as a place for family and friends gathering. }\end{array}$ \\
\cline { 2 - 4 } & $\begin{array}{l}\text { Non-use } \\
\text { value }\end{array}$ & $\begin{array}{l}\text { Respondents value the existence of their vernacular houses } \\
\text { even though they may not consume their services directly } \\
\text { themselves. } \\
\text { People wish to maintain the option that they or their sons might } \\
\text { consume the asset's services at some future time. } \\
\text { People wish to bequeath their vernacular assets to future } \\
\text { generations. }\end{array}$ \\
\hline Cultural & Communal & $\begin{array}{l}\text { Communal value relates to the meanings of a place for people, } \\
\text { and the collective experience or memory it holds. Respondents } \\
\text { perceived their vernacular houses as a source of identity. }\end{array}$ \\
\cline { 2 - 4 } & Evidential & $\begin{array}{l}\text { Respondents appreciate the vernacular buildings as a source of } \\
\text { evidence about the evolution of their places, and of the people } \\
\text { and cultures that created them. They are part of a unique record } \\
\text { of their past. }\end{array}$ \\
\hline Aesthetic & $\begin{array}{l}\text { Respondents appreciate the aesthetic qualities generated by the } \\
\text { conscious design and stewardship of their old houses. Design } \\
\text { value embraces materials, decoration, craftsmanship and } \\
\text { adaptability to social and climatic conditions }\end{array}$ \\
\hline
\end{tabular}

was promoted, as a new way of life, to correspond to modern social needs, new materials, technology and new aesthetic ideals. Other changes, such as governmental development and road networks, have caused the image of the cities and villages to be divorced from the particularities of place [22]. Table 2 summarizes the values based on the research outcomes.

\section{CONCLUSION AND RECOMMENDATIONS}

This research partially conveys the dichotomy between the longing for a contemporary lifestyle but also a feeling of lost values and traditions. Yet more importantly perhaps, these accounts prove that culture, history, and architecture are interrelated concepts, which cannot be understood in isolation from one another. The meanings we assign to physical forms, in reality, do not only exist within the structures themselves but also in the knowledge and experiences accumulated over time. Therefore, it is only through an understanding of inherited values, environmental conditions and anthropological history grounded in contemporary realities that it would seem possible to recreate settings that provide people with a sense of place, identity and belonging.

Thus, what seems to be needed is an integrated and participatory strategy of restoration, adaptive reuse and intergenerational knowledge exchange that involves the local community as well as government agencies to effectively ignite an awareness of the economic and cultural potential that many of these privately-owned properties could bring to the region. An active encouragement of the use of vernacular building practices along with the promotion 
of alternative technologies could initiate a sustainable process of adaptive reuse. Undoubtedly, also viable public/private partnerships play a vital role in this equation where government agencies might ease certain restrictions and provide financial incentives while owners also have a monetary stake in the process to achieve a balance between public commitment, private investments, and community initiatives.

In addition, a collective educational program needs to be created to build public awareness, particularly among the younger generation to foster engagement and help to increase the community's understanding and relationship with the tangible and intangible heritage concerning its conservation and sustainable development. This can be achieved, for example, through the creation of an interdisciplinary and intergenerational learning platform where seasoned elders skilled in traditional building techniques and other art forms receive an opportunity to apply their skills and furthermore enrich their artistic knowledge by teaching younger members in the community. At the same time, they will have the prospect of gaining new skills from invited experts who specialize in new technologies and who, in return, will benefit from local practices. In this way, elder community members, many are currently live off government support, will find a renewed meaning in their tradition and pass their original expertise of art and craft to younger members and students some of who can bring technical knowledge from their course of study at the universities. In summation, a sustainable revitalization of rural vernacular cultures commands an interactive, participatory and entrepreneurial process, which actively involves all members of the community, branches of government as well as private and public-sector agencies to facilitate the necessary financing, resources, and skills and - perhaps most importantly - the effective exchange of knowledge and ideas.

\section{ACKNOWLEDGEMENTS}

This paper has been developed from the outcomes of a research project entitled: Developing intergenerational knowledge transfer of vernacular building techniques in the southwest of Saudi Arabia, initiated by Anna Klingmann in 2016. The research project was funded by Effat University, Jeddah, Saudi Arabia and carried out by the authors and a team of students at the school of Architecture and Design. The authors would like to thank Effat University for supporting this project and all the students for their contribution to this research paper.

\section{REFERENCES}

[1] Bagader, M., The evolution of built-heritage conservation concept in Saudi Arabia since the 1970's till 2014. Research \& Heritage 4: The Saudi Commission for Tourism and Antiquities, Riyadh, 2014.

[2] The Nara Document on Authenticity, 1994. Online. http://whc.unesco.org/archive/ nara94.htm. Accessed on: Aug. 2011.

[3] Throsby, D., Cultural capital and sustainability concepts in the economics of cultural heritage. Assessing the Values of Cultural Heritage, The J. Paul Getty Trust: Los Angeles, p. 103, 2002.

[4] Giannakopolou, S. \& Kaliampakos, D., Assessing the Economic Value of Vernacular Architecture of Mountain Regions Using Contingent Valuation. School of Mining and Metallurgical Engineering, National Technical University of Athens, Science Press and Institute of Mountain Hazards and Environment/CAS and Springer-Verlag Berlin: Heidelberg, p. 630, 2011.

[5] Kalamarova, M., Loucanova, E., Parobek, J. \& Supin, M., The support of the cultural heritage utilization in historical town reserves. ScienceDirect Procedia Economics and Finance, 26, pp. 914-919, 2015. 
[6] Riganti, P. \& Nijkamp, P., Valuing cultural heritage benefits to urban and regional development. Proceedings of the 44th Congress of the European Regional Science Association: Regions and Fiscal Federalism, Portugal, 25th-29th Aug. 2004.

[7] Klamer, A., Accounting for social and cultural values. De Economist, 150(4), p. 467, 2002.

[8] Ruijgrok, E.C.M., The three economic values of cultural heritage: a case study in The Netherlands. Journal of Cultural Heritage, 7, pp. 206-213, 2006.

[9] Riganti, P. \& Nijkamp, P., Valuing cultural heritage. Cultural Tourism and sustainable local development, eds L. Fusco Grirad \& P. Nijkamp, Routledge, 2009.

[10] Yüceer, H. \& Ipekoğlu, B., An architectural assessment method for new exterior additions to historic buildings. Journal of Cultural Heritage, 13(4), pp. 419-425, 2012.

[11] Convention for the safeguarding of the intangible cultural heritage, 2003. Online http://unesdoc.unesco.org/images/0013/001325/132540e.pdf. Accessed on: Jan. 2018

[12] Norma, E. \& Cervantes, R., Urban conservation in Mexican Colonial cities: the historic centre of Morelia. Designing Sustainable Cities in the Developing World, eds R. Zetter $\&$ B. Watson, Antony Rowe Ltd.: Wiltshire, 2007.

[13] Wang, H. \& Zeng, Z., A multi-objective decision-making process for reuse selection of historic buildings. Expert Systems with Applications, 37(2), 2010.

[14] Mason, R., Assessing values in conservation planning: methodological issues and choices. Assessing the Values of Cultural Heritage: Research Report, ed. M.D. Torre, Getty Conservation Institute: Los Angeles, CA, 2002.

[15] Low, S.M., Anthropological-ethnographic methods for the assessment of cultural values in heritage conservation. Assessing the values of cultural heritage: research report, ed. M.D. Torre. Getty Conservation Institute: Los Angeles, CA, 2002.

[16] Nelsson, S., Environment and design notes on the vernacular and architecture of the Asir. Environmental Design: Journal of the Islamic Environmental Design Research Centre 2. Water and Architecture, ed. A. Petruccioli, Carucci Editions: Rome, 1985.

[17] Mohamed, M., Traditional ways of dealing with climate in Egypt. Proceedings of the Seventh International Conference of Sustainable Architecture and Urban Development, Amman, eds J.S. Lehmann, H.A. Waer \& J. Al-Qawasmi, The Center for the Study of Architecture in Arab Region (CSAAR Press), 1, pp. 247-266, 2010.

[18] Throsby, D., Conceptualizing heritage as cultural capital. Proceedings of Heritage Economics: Challenges for Heritage Conservation and Sustainable Development in the 21st Century, July 4, 2000, Australian National University: Canberra, 2000.

[19] Drury, P. \& MacPherson, A., Conservation Principles: Policies and Guidance for the Sustainable Management of the Historic Environment, English Heritage: London, 2008.

[20] Rapoport, A., History and Precedent in Environmental Design, Plenum Publishing Corporation: New York.

[21] Saleh, M.A.E., Place identity: The visual image of Saudi Arabian cities. Habitat International, 22(2), pp. 149-164, 1998.

[22] Saleh, M.A., Environmental cognition in the vernacular landscape: assessing the aesthetic quality of Al-Alkhalaf village, Southwestern Saudi Arabia. Building and Environment, 36(8), pp. 965-979, 2001. 